\title{
Impact of Catchment Scale on Rainfall Runoff Modeling: Kalu Ganga River Catchment upto Ratnapura
}

\author{
D.P.H.M. Kanchanamala, H.M.H.K. Herath and K.D.W. Nandalal
}

\begin{abstract}
Lumped rainfall-runoff models are popular among hydrologists as they are convenient for modeling basins. The accuracy of a lumped model could be increased by dividing the catchment into several sub-catchments to represent variations in the basin. This paper discusses the improvements that could be achieved by considering a catchment in several sub-catchments. In this study, lumped model HEC-HMS has been used to model Kalu Ganga River catchment upto Ratnapura. The paper compares the diverse modeling methods available in the HEC-HMS software for modeling losses, modeling transformation of rainfall to runoff and modeling baseflow. The results indicate that the performance of the rainfall-runoff model significantly improves when the basin is modeled in many sub-catchments. Further, the study shows that alternative methods available for loss, transform and baseflow in the HEC-HMS perform differently. For Kalu Ganga River basin the deficit constant method, Snyder unit hydrograph method and recession method were found to be the most suitable methods for the three components.
\end{abstract}

Keywords: Rainfall-runoff modeling, scale effect, HEC-HMS.

\section{Introduction}

Rainfall-runoff modeling or hydrological modeling is a major component in a hydrological study. There have been two major approaches in rainfall-runoff modeling, viz., (i) distributed modeling, and (ii) lumped modeling. The runoff is taken as a function of both temporal variability and spatial variability in distributed modeling while the runoff is only a function of time in lumped modeling. The distributed hydrological modeling is found to be more accurate than the lumped hydrological modeling. However, distributed hydrological modeling is tedious and requires more data, effort and time. Therefore, lumped hydrological modeling is found to be more popular among modelers as it is less cumbersome.

The development of distributed hydrological models and their use in investigating spatial variability and scale effect have been reported by many [1, 2, 3, 4]. An application of a distributed model, TOPMODEL, to a catchment in North Carolina, USA to investigate the effect of scale showed that a representative elementary area does exist in the context of runoff generation [1]. Further, the study revealed that topography through the size and shape of sub catchments has a strong influence on the runoff while variability of soils and rainfalls has only a secondary role.
Another study carried out to investigate the effect of scale using the model KINEROS showed that the runoff per unit area decreases as sub catchment size increases [2].An investigation carried out on the impact of spatial variability and scale on the dynamics of hydrological processes based on Monongahela river basin of the USA revealed that physical processes governing rainfall-runoff response, change with spatial resolution [3].The effects of spatial input data resolution on hydrological modeling investigated using distributed hydrological model PCRXAJ indicated that an increase in the grid size causes loss of important information and that it thus results in a decrease in the model efficiency [4].

Similarly, the impact of spatial variability on the rainfall-runoff process in relatively simple lumped hydrological models has been investigated $[5,6]$. For example, an investigation of the effect of spatially different

\footnotetext{
Miss. D.P.H.M. Kanchanamala, BSc(Eng)Hons., Department of Civil Engineering, University of Peradeniya.

Miss. H.M.H.K. Herath, BSc(Eng)Hons., Department of Civil Engineering, University of Peradeniya.

Eng.(Prof.) K.D.W. Nandalal, BSc(Eng)Hons., MEng(AIT), PhD(The Netherlands), FIE(Sri

Lanka), CEng. Senior Professor, Department of Civil Engineering, University of Peradeniya.
} 
rainfall fields in simulating runoff and erosion carried out using the lumped model THALES revealed that spatial variability in rainfall has only a minor impact on runoff processes and on the spatial variability of runoff and erosion parameters [5]. The effects of a uniform versus distributed spatial account of rainfall and soil/land use spatial representation through the comparison of simulated flood hydrographs has been analysed[7]. Studies on the effect of slope and river on runoff according to the spatial scale of catchments selected have been carried out [8]. The effect of watershed subdivision on calibrated model parameter values, description of hydrological processes, and subsequent interpretation of water balance components using the HEC HMS model have been reported [9]. Hydrological modeling has become an important element in many water resources projects in Sri Lanka and thus the possibility to use simple lumped hydrological models in the most efficient and accurate manner was interesting to study. The impact of dividing a catchment into several sub-catchments in the modeling of rainfall-runoff process in the Sri Lankan context was thus of interest. This paper presents an investigation on the possibility of improving the accuracy of the use of a lumped hydrological model by dividing a catchment into several subcatchments making use of Kalu Ganga River catchment up to Ratnapura through the software HEC HMS. Furthermore, the identification of the most suitable modeling methods from among various alternative methods available in the HEC HMS software is also presented in the paper.

\section{Study Area}

A sub-catchment of KaluGanga River basin in Sri Lanka upto Ratnapura as shown in Figure 1 was used for the study. The study catchment is entirely situated in the wet zone of the country and it has a high rainfall to runoff response. The study catchment located to the southwest and south of the central highlands lies between $80.40^{\circ}$ and $80.73^{\circ}$ Elongitude and $6.53^{\circ}$ and $6.80^{\circ}$ Nlatitude. It covers an area of about $603 \mathrm{~km}^{2}$ with an annual flow of about 1572 million $\mathrm{m}^{3}$ measured at Ratnapura. Generally, the elevation varies from $20 \mathrm{~m}$ to $2225 \mathrm{~m}$ from MSL and the average slope of the catchment varies from $10^{\circ} \circ$ to $35^{\circ} \circ$ in the upland ridges. The annual precipitation within the catchment is above $4000 \mathrm{~mm}$, and the catchment receives its highest precipitation during May to July every year.

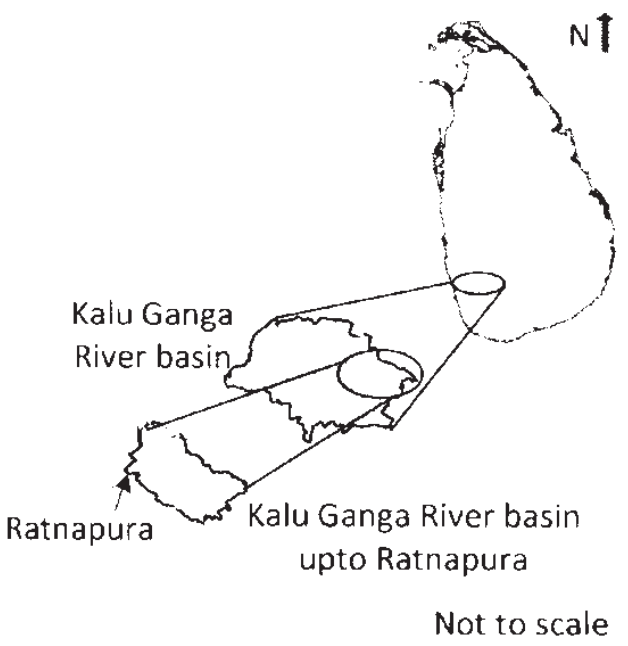

Figure 1 - Location of KaluGanga River Basin

\section{Methodology}

There are 7 rainfall gauging stations in and around the catchment as shown in Table 1. Daily rainfalls at these stations from 1986 to 2008 were collected from the Department of Meteorology. Discharge data of the KaluGanga River from 1986 to 1996 at Ratnapura were gathered from the Department of Irrigation.

Table 1 - Rainfall Gauging Stations

\begin{tabular}{llrlr}
\hline $\begin{array}{l}\text { Rainfall Gauging } \\
\text { Station }\end{array}$ & Lat & Lon & $\begin{array}{r}\text { Elevation } \\
(\mathrm{m})\end{array}$ & MSL \\
\hline Kuruwita & $6.80 \mathrm{~N}$ & 80.36 & $\mathrm{E}$ & 121.9 \\
Lellopitiya Estate & $6.68 \mathrm{~N}$ & 80.50 & $\mathrm{E}$ & 279.0 \\
Ratnapura & $6.68 \mathrm{~N}$ & 80.40 & $\mathrm{E}$ & 34.4 \\
Wellandura Estate & $6.53 \mathrm{~N}$ & 80.57 & $\mathrm{E}$ & 305.0 \\
Alupolla & $6.72 \mathrm{~N}$ & 80.58 & $\mathrm{E}$ & 762.5 \\
Hapugastenna & $6.72 \mathrm{~N}$ & 80.52 & $\mathrm{E}$ & 594.5 \\
Balangoda & $6.65 \mathrm{~N}$ & 80.70 & $\mathrm{E}$ & 527.4 \\
\hline
\end{tabular}

The locations of the rainfall gauging stations and the stream flow gauging station are presented in Figure 2. 


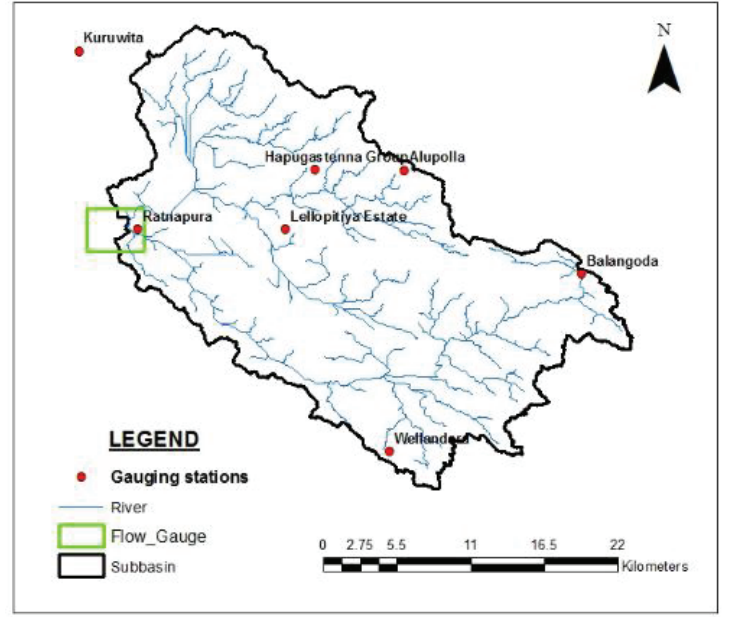

Figure 2 - Kalu River Sub Catchment above Ratnapura

Initially, rainfall data at all of the seven stations was screened using the procedure given by Dahmen and Hall[10]. The process started with a rough screening, which allows visual detection as to whether the observations have been consistently or accidentally credited to a wrong day, whether they show gross errors or whether they contain misplaced decimal points. Then the data was plotted on a graph to see whether there are any obvious trends or discontinuities. To make sure that there is no correlation between the order in which the data has been collected and the increase (or decrease) in magnitude of that data, the series were tested for absence of a trend using Spearman's rank-correlation method. Then the data series was tested for the stability of variance and mean. An instability of variance implies that the data series is not stationary. Finally, the data series was tested for absence of persistence using lag 1 serialcorrelation coefficient. These checks endorsed that the data was suitable for use in the study.

The basin boundary was developed using Digital Elevation Model (DEM) data. Shuttle Radar Topography Mission (SRTM) DEM data with $30 \mathrm{~m}$ grid resolution [11] was used for this purpose. Major steps adopted in the study are given in Figure 3.

As indicated in Figure 3, Arc-GIS (10.2) software was used for the development of catchment boundaries and other relevant hydrological parameters. Three different catchment configurations were studied. That is the catchment upto Ratnapura as (i) one catchment, (ii) comprising of six sub catchments, and (iii) comprising of nine sub catchments.

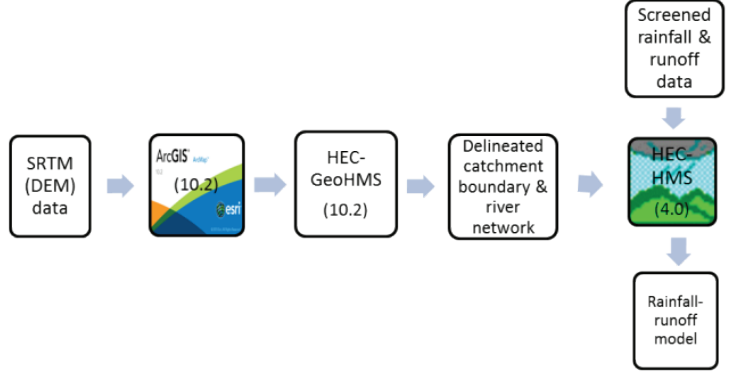

Figure 3 - Methodology Adopted

These sub catchments shown in Figure 4 were developed mainly based on the river network and other catchment spatial characteristics such as slope, land use, etc. Hydrological models for the three different catchment configurations developed in HEC-GeoHMS in Arc-GIS environment were exported to HECHMS (version 4.0).
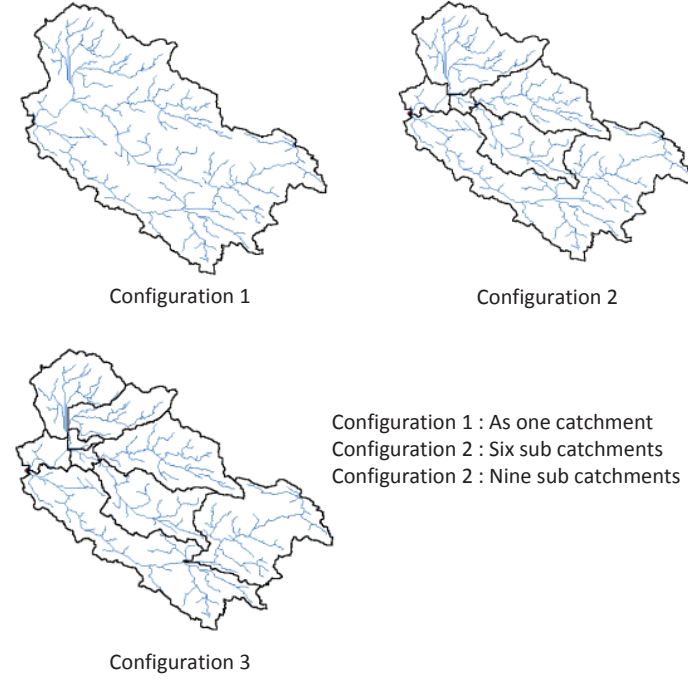

Figure 4 - Three Catchment Configurations

The HEC-HMS based hydrological rainfallrunoff model consists of a loss component, a transfer component and a base flow component. The model has several different methods available for use with these components. It was also intended to study the applicability of these methods for Kalu river catchment in addition to investigating the impacts of different catchment scales on rainfall-runoff predicting accuracy.

For the loss component Initial/Constant, SCS curve number and Deficit/Constant methods available in the HEC-HMS software were studied for their applicability to Kalu river basin. Clark Unit hydrograph, Snyder's model and SCS Unit hydrograph methods were the rainfall-runoff conversion methods studied. 
For the base flow, the suitability of two base flow methods available in HEC-HMS, viz., constant monthly method and recession method were studied. For each catchment configuration, 18 different combinations of loss component, transfer component and base flow component were used as shown in Table 2.

Table 2 - Method Combinations used in the Study

\begin{tabular}{|c|c|c|c|c|c|c|c|c|}
\hline \multirow{2}{*}{ 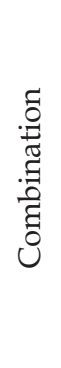 } & \multicolumn{3}{|c|}{ 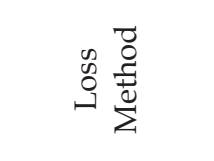 } & \multicolumn{3}{|c|}{ 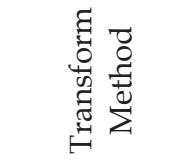 } & \multicolumn{2}{|c|}{$\begin{array}{l}3 \\
0 \\
0 \\
0 \\
0 \\
0 \\
0 \\
0 \\
0 \\
0\end{array}$} \\
\hline & 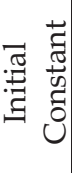 & 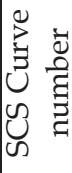 & 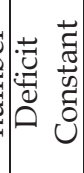 & $\begin{array}{l}\frac{I}{J} \\
\frac{y}{d} \\
\frac{\pi}{U}\end{array}$ & 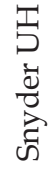 & 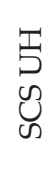 & 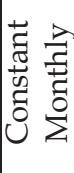 & 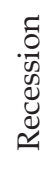 \\
\hline 1 & $\sqrt{ }$ & - & - & $\sqrt{ }$ & - & - & $\sqrt{ }$ & - \\
\hline 2 & $\sqrt{ }$ & - & - & $\sqrt{ }$ & - & - & - & $\sqrt{ }$ \\
\hline 3 & $\sqrt{ }$ & - & - & - & $\sqrt{ }$ & - & $\sqrt{ }$ & - \\
\hline 4 & $\sqrt{ }$ & - & - & - & $\sqrt{ }$ & - & - & $\sqrt{ }$ \\
\hline 5 & $\sqrt{ }$ & - & - & - & - & $\sqrt{ }$ & $\sqrt{ }$ & - \\
\hline 6 & $\sqrt{ }$ & - & - & - & - & $\sqrt{ }$ & - & $\sqrt{ }$ \\
\hline 7 & - & $\sqrt{ }$ & - & $\sqrt{ }$ & - & - & $\sqrt{ }$ & - \\
\hline 8 & - & $\sqrt{ }$ & - & $\sqrt{ }$ & - & - & - & $\sqrt{ }$ \\
\hline 9 & - & $\sqrt{ }$ & - & & $\sqrt{ }$ & - & $\sqrt{ }$ & - \\
\hline 10 & - & $\sqrt{ }$ & - & - & $\sqrt{ }$ & - & - & $\sqrt{ }$ \\
\hline 11 & - & $\sqrt{ }$ & - & - & - & $\sqrt{ }$ & $\sqrt{ }$ & \\
\hline 12 & - & $\sqrt{ }$ & - & - & - & $\sqrt{ }$ & - & $\sqrt{ }$ \\
\hline 13 & & - & $\sqrt{ }$ & $\sqrt{ }$ & - & - & $\sqrt{ }$ & - \\
\hline 14 & - & - & $\sqrt{ }$ & $\sqrt{ }$ & - & - & - & $\sqrt{ }$ \\
\hline 15 & - & - & $\sqrt{ }$ & - & $\sqrt{ }$ & - & $\sqrt{ }$ & - \\
\hline 16 & - & - & $\sqrt{ }$ & - & $\sqrt{ }$ & - & - & $\sqrt{ }$ \\
\hline 17 & - & - & $\sqrt{ }$ & - & - & $\sqrt{ }$ & $\sqrt{ }$ & - \\
\hline 18 & - & - & $\sqrt{ }$ & - & - & $\sqrt{ }$ & - & $\sqrt{ }$ \\
\hline
\end{tabular}

The Thiessen Polygon method was used to average rainfall over sub-catchments. After developing HEC-HMS based rainfall-runoff models for the three configurations, the three models were calibrated. Rainfall data and runoff data for the five years from 1986 to 1990 were used for the calibration. Parameters of the models were determined by the parameter optimization procedure available in the HECHMS model. However, an iterative procedure had to be applied when determining optimum parameter values.
Subsequently, the calibrated models were verified for the period from 1991 to 1995. The HEC-HMS based rainfall-runoff model performances for all the alternative catchment configurations based on the model resulted flow data were compared with the actual discharge data. The comparisons were performed by visual checks and comparing Nash-Sutcliffe coefficient values.

The Nash-Sutcliffe coefficient evaluates the predicting power of a hydrological model. The value varies in between $-\infty$ to 1 . Models with a coefficient value of more than 0 provide a better model performance. It is calculated as;

$E=1-\frac{\sum_{t=1}^{T}\left(Q_{o}^{t}-Q_{m}^{t}\right)^{2}}{\sum_{t=1}^{T}\left(Q_{o}^{t}-\overline{Q_{o}}\right)^{2}}$

where,
$Q_{o}$ - Mean observed discharge
$Q_{m}$ - Modeled discharge
$Q_{o}{ }^{t}$ - Observed discharge at time $\mathrm{t}$

\section{Analysis and Results}

As mentioned in the previous section, catchment area boundaries and hydrological parameters of the three catchment configurations were developed using HECGeoHMS software in an ArcGIS (10.2) environment. Subsequently, this information was exported to HEC-HMS (Ver 4.0) to develop three rainfall-runoff models. Figure 5 shows the HEC-HMS based model for the second configuration. Similarly, rainfall-runoff models for the other two basins were also developed.

The model parameters of all the abovementioned model combinations were determined during the calibration process using rainfall and runoff data for the period from 1986 to 1990. The calibration process initializes with a simulation run and is followed by parameter optimizations, which is done iteratively. The number of parameters differs with the model combination. For all the model combinations, optimization trials were run separately. At these trials the NashSutcliffe coefficients were noted. The trials were continued until acceptable NashSutcliffe coefficient values were obtained. At the calibration stage, the Nash-Sutcliffe coefficients for the second configuration were observed to be higher than those for the first configuration. However, the third 
configuration did not show a notable increase in the Nash-Sutcliffe coefficient.

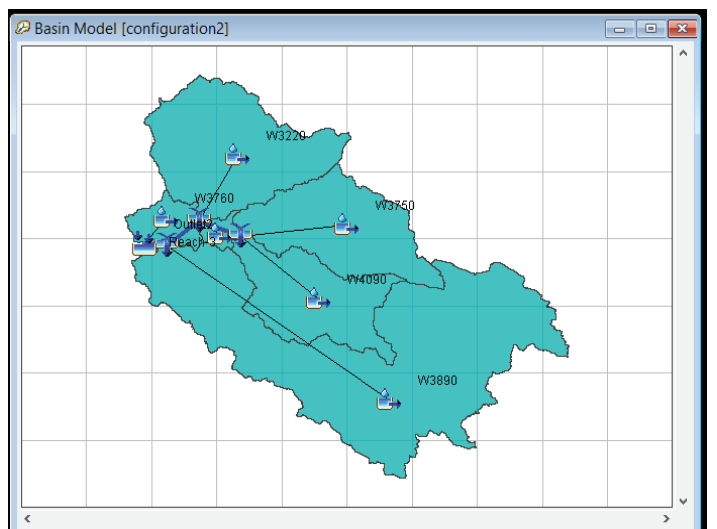

Figure 5 - HEC- HMS model: Configuration 2

Finally, the calibrated models were verified using data of the period from 1991 to 1995.Then HEC-HMS based rainfall-runoff model performances for all the alternative

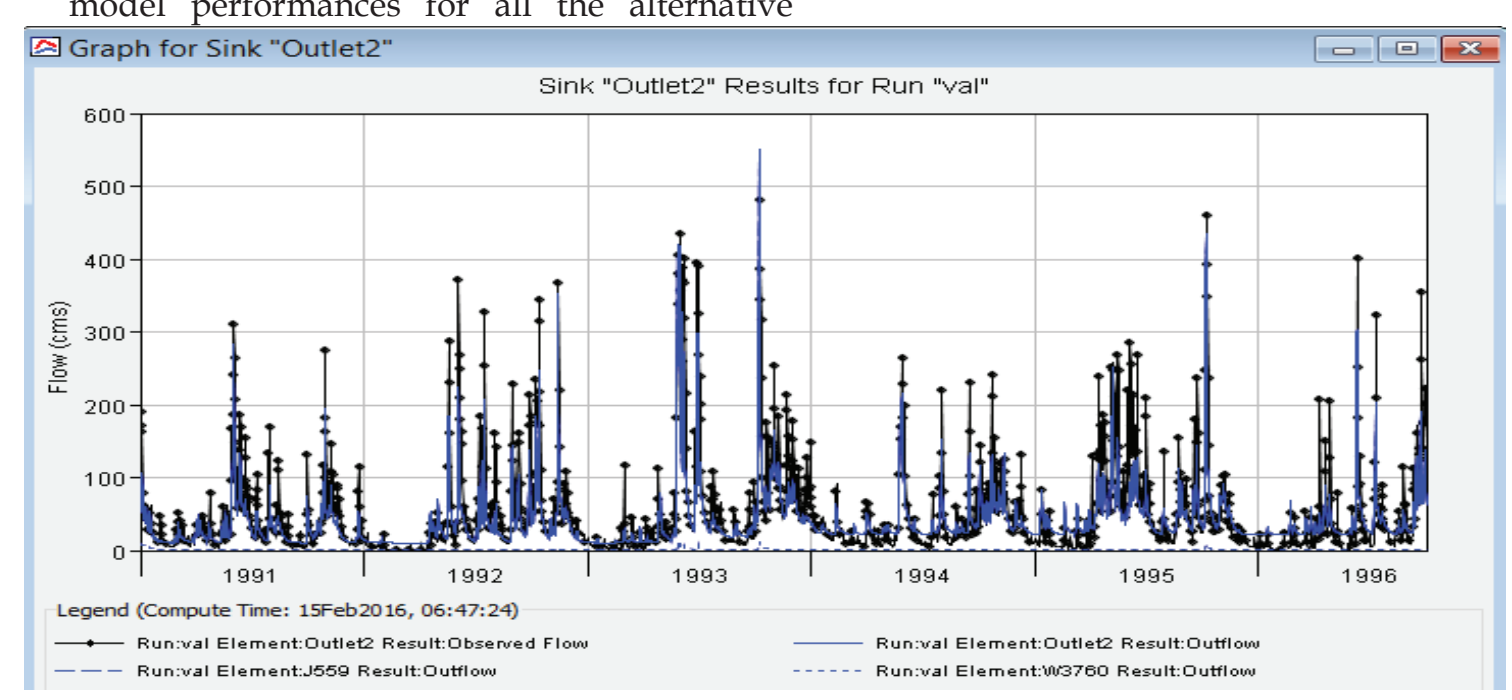

Figure 6 - Observed and Computed Discharges: Configuration 2, Model Combination 16

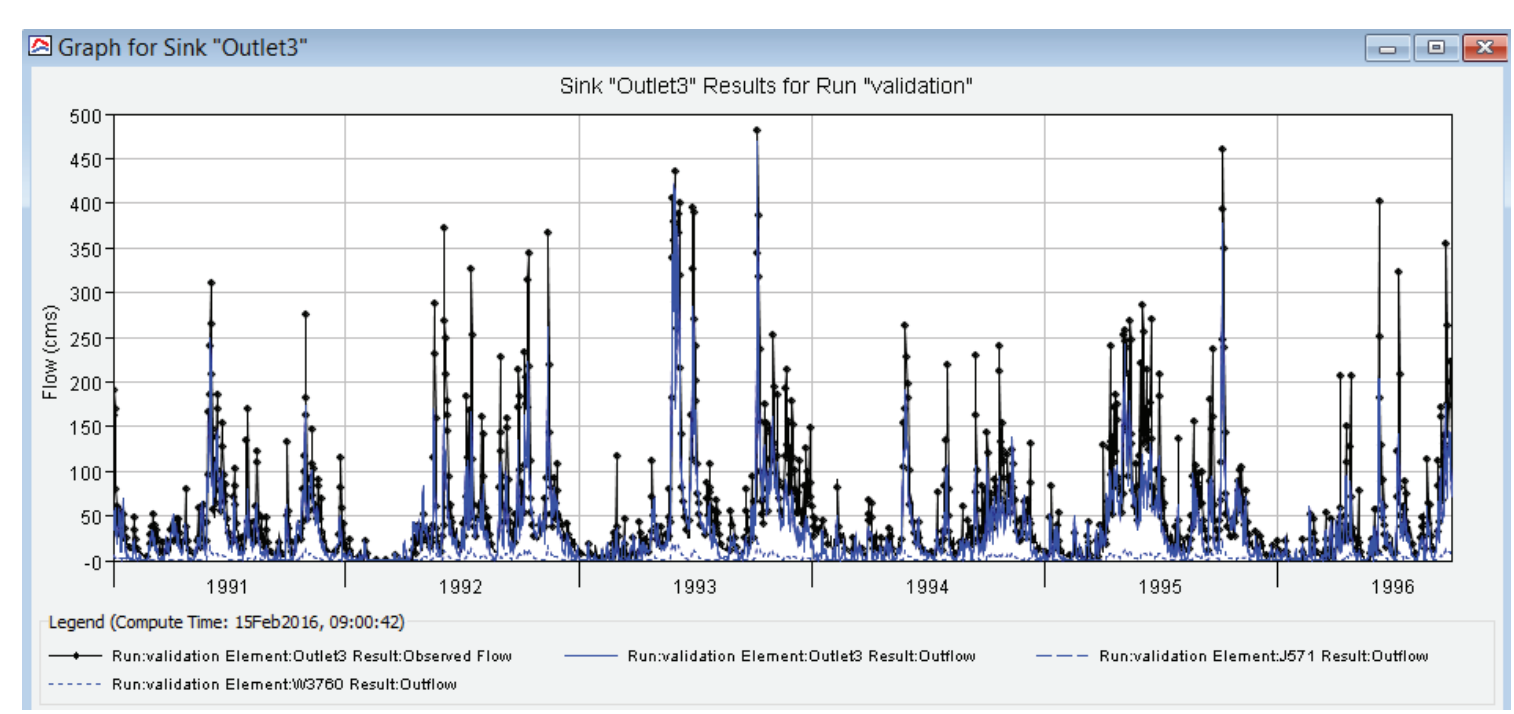

Figure 7 - Observed and Computed Discharges: Configuration 3, Model Combination 16 catchment configurations (18 models per configuration) were compared based on the model resulted flow data with the actual flow data. The comparisons were performed based on a visual check and the Nash-Sutcliffe coefficient.

The plots of observed discharge and computed discharge were compared for every model combination through visual checks. Figures 6 and 7 are examples of the plots of observed discharge and computed discharge of model combination 16 of the catchment configurations 2 and 3.

The applicability of the model results for the future forecasting of runoff is ensured by validating the model. Nash- Sutcliffe coefficients obtained in the verification are given in Table 3. 
Table 3 - Nash - Sutcliffe Coefficient at Validation Trials

Nash - Sutcliffe Coefficient

\begin{tabular}{|c|c|c|c|}
\hline 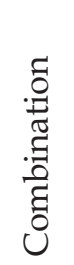 & 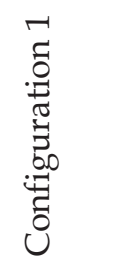 & 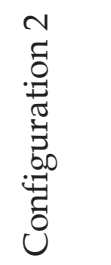 & 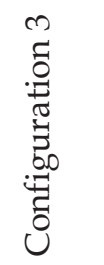 \\
\hline 1 & 0.492 & 0.740 & 0.581 \\
\hline 2 & 0.421 & 0.729 & 0.676 \\
\hline 3 & 0.731 & 0.790 & 0.560 \\
\hline 4 & 0.690 & 0.808 & 0.794 \\
\hline 5 & 0.172 & 0.706 & 0.549 \\
\hline 6 & 0.171 & 0.770 & 0.661 \\
\hline 7 & 0.209 & 0.438 & 0.257 \\
\hline 8 & 0.264 & 0.668 & 0.632 \\
\hline 9 & 0.240 & 0.441 & 0.220 \\
\hline 10 & 0.229 & 0.685 & 0.663 \\
\hline 11 & -0.010 & 0.446 & 0.208 \\
\hline 12 & 0.010 & 0.682 & 0.627 \\
\hline 13 & 0.479 & 0.735 & 0.613 \\
\hline 14 & 0.627 & 0.764 & 0.709 \\
\hline 15 & 0.527 & 0.758 & 0.559 \\
\hline 16 & 0.700 & 0.752 & 0.761 \\
\hline 17 & 0.274 & 0.731 & 0.588 \\
\hline 18 & 0.345 & 0.784 & 0.731 \\
\hline
\end{tabular}

Nash-Sutcliffe coefficients for different combinations are compared in Figure 8. Their variation is observed to be similar to NashSutcliffe coefficients obtained at the calibration process.

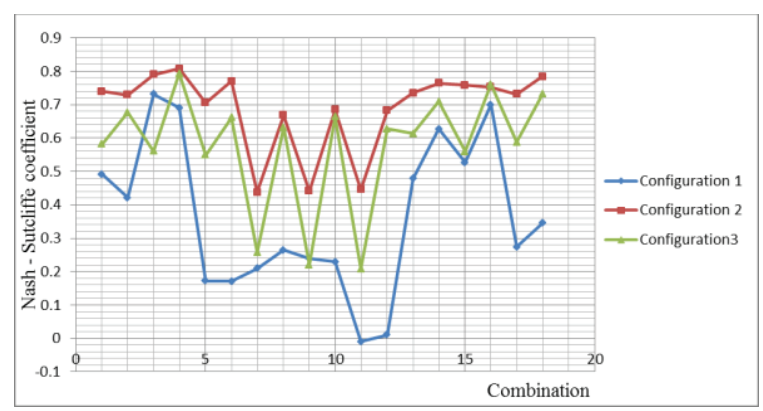

Figure 8 - Comparison of Nash-Sutcliffe Coefficients for different Configurations

Figure 8 indicates that model performances increase from Configuration 1 to
Configuration 2. However, performances of Configuration 3 are inferior to those of Configuration 2 though the number of subcatchments has been increased. It suggests that increasing the number of sub-catchments does not always increase model performances. The combination 16 seems to be showing more or less the same performance with all the three configurations.

Since the Configuration 2 was observed to be the most preferable one, the model combinations for that configuration were ranked according to their performances. Table 4 presents the ranking of model combinations based on Nash-Sutcliffe coefficients.

Table 4 - Ranked Model Combination in Configuration 2

\begin{tabular}{|c|c|c|c|c|c|c|c|c|c|}
\hline \multirow[b]{2}{*}{ 䒕 } & \multirow[b]{2}{*}{ 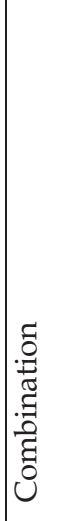 } & \multicolumn{3}{|c|}{ 焉 } & \multicolumn{3}{|c|}{ 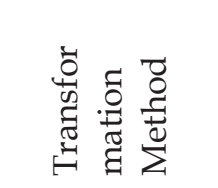 } & \multicolumn{2}{|c|}{ 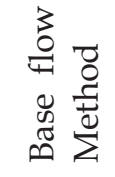 } \\
\hline & & 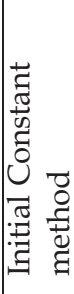 & 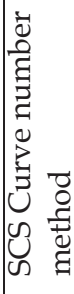 & 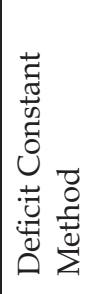 & 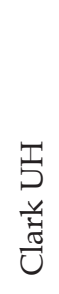 & 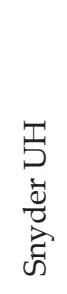 & 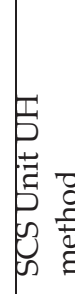 & 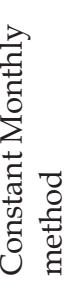 & 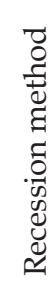 \\
\hline 1 & 16 & & & $\sqrt{ }$ & & $\sqrt{ }$ & & & $\sqrt{ }$ \\
\hline 2 & 15 & & & $\sqrt{ }$ & & $\sqrt{ }$ & & $\sqrt{ }$ & \\
\hline 3 & 2 & $\sqrt{ }$ & & & $\sqrt{ }$ & & & & $\sqrt{ }$ \\
\hline 4 & 17 & & & $\sqrt{ }$ & & & $\sqrt{ }$ & $\sqrt{ }$ & \\
\hline 5 & 3 & $\sqrt{ }$ & & & & $\sqrt{ }$ & & $\sqrt{ }$ & \\
\hline 6 & 1 & $\sqrt{ }$ & & & $\sqrt{ }$ & & & $\sqrt{ }$ & \\
\hline 7 & 6 & $\sqrt{ }$ & & & & & $\sqrt{ }$ & & $\sqrt{ }$ \\
\hline 8 & 13 & & & $\sqrt{ }$ & $\sqrt{ }$ & & & $\sqrt{ }$ & \\
\hline 9 & 4 & $\sqrt{ }$ & & & & $\sqrt{ }$ & & & $\sqrt{ }$ \\
\hline 10 & 14 & & & $\sqrt{ }$ & $\sqrt{ }$ & & & & $\sqrt{ }$ \\
\hline 11 & 5 & $\sqrt{ }$ & & & & & $\sqrt{ }$ & $\sqrt{ }$ & \\
\hline 12 & 18 & & & $\sqrt{ }$ & & & $\sqrt{ }$ & & $\sqrt{ }$ \\
\hline 13 & 12 & & $\sqrt{ }$ & & & & $\sqrt{ }$ & & $\sqrt{ }$ \\
\hline 14 & 10 & & $\sqrt{ }$ & & & $\sqrt{ }$ & & & $\sqrt{ }$ \\
\hline 15 & 8 & & $\sqrt{ }$ & & $\sqrt{ }$ & & & & $\sqrt{ }$ \\
\hline 16 & 11 & & $\sqrt{ }$ & & & & $\sqrt{ }$ & $\sqrt{ }$ & \\
\hline 17 & 9 & & & $\sqrt{ }$ & & & $\sqrt{ }$ & $\sqrt{ }$ & \\
\hline 18 & 7 & & & $\sqrt{ }$ & & & $\sqrt{ }$ & & $\sqrt{ }$ \\
\hline
\end{tabular}




\section{Conclusions}

The impact of increasing the number of subbasins on the prediction accuracy of runoff was studied. It was observed that increasing the number of sub-basins to six from one would increase rainfall-runoff model performances. This improvement was noted for all the method combinations studied. The Nash- Sutcliffe coefficient was mainly used for the comparison of model performances.

Nevertheless, the third configuration in which the basin was divided into nine sub-basins did not result in any further improvement. This suggests that dividing a catchment into subcatchments mainly depending on stream network is not always helpful in improving model performances. Along with the stream network, other important characteristics such as soil properties, land cover, etc., need also to be considered during the division of the catchment into sub-catchments for improving model performances. It could be suggested that the performance of lumped hydrological models could be definitely improved by modeling a catchment in many subcatchments, but having a large number of subcatchments with more or less similar properties may also not be very useful. Thus, a modeler needs to consider along with the stream network, other catchment properties such as, soil properties, land cover, land use, slope, etc., when dividing a catchment into sub-catchments.

The model behavior was irregular with the model combinations studied. High NashSutcliffe coefficients resulted in models which used recession method as the base flow method, compared to other models in the third configuration. The sixteenth model combination demonstrated a gradual increase in the Nash-Sutcliffe coefficient when the number of sub catchments progressively increased.

Based on the results, the most suitable set of parameter combination for the Kalu Ganga upper catchment was decided as Deficit Constant method as the loss method, Snyder Unit Hydrograph method as the transformation method and Recession method as the base flow method.

\section{References}

[1] Wood, E. F., Sivapalan, M., Beven, K., Band, L., 1988. Effects of Spatial Variability and Scale with Implications to Hydrologic Modeling. Journal of Hydrology, 102, pp.29-47.

[2] Canfield, H. E., Goodrich, D. C., 2011. Studies of Scale and Processes in Hydrologic Modeling on the Lucky Hills watershed. [Online] Available at: http://www.docstoc.com [Accessed

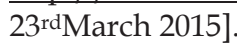

[3] Yildiz, O., Barros, P., 2009. Evaluating Spatial Variability and Scale Effects on Hydrologic Processes in a Midsize River Basin. Scientific Research and Essay, 4(4), pp.217-25.

[4] Zhao, G. J., Fohrer, N., Gao, J. F., 2009. Impacts of Spatial Data Resolution on Simulated Discharge, A Case Study of XitiaoxiCatchment in South China. Advances in Geo Sciences, 21, pp.131-37.

[5] Adams, R., Western, A. W., Seed, A. W., 2012. An Analysis of the Impact of Spatial Variability in Rainfall on Runoff and Sediment Predictions from a Distributed Model. HYDROLOGICAL PROCESSES, 26, pp.326380.

[6] Mimikou, M., 1984. Regional Relationships between Basin Size and Runoff Characteristics. Hydrological Sciences, 29, pp.13.

[7] Berni, N., Viterbo, A., Pandolfo, C., Stelluti, M., Barbetta, S., Brocca, L., 2008. Effects of Rainfall and Soil/Land Use Spatial Distribution on Hydrological Response at Different Scales. In International Congress on Environmental Modeling and Software Integrating Sciences and Information Technology for Environmental Assessment and Decision Making.

[8] Kure, S., Tomizawa, A., Ebana, R., Yamada, T., 2008. Effects of Spatial Distribution of Hydrological Characteristics on Runoff According to the Spatial Scale of Catchment. In World Environmental and Water Resources Congress. Ahupua'a.

[9] Zhang, H. L., Wang, Y. J., Wang, Y. Q., Li, D. X., Wang, X. K., 2013. The Effect of Watershed Scale on HEC-HMS Calibrated Parameters: A Case Study in the Clear Creek Watershed in Iow a, US. Hydrology and Earth System Sciences, 17, pp.2735-45.

[10] Dahmen, E. R., Hall, M. J. (1990). Screening of hydrological data: Tests for stationarity and relative consistency.

[11] SRTM 90m Digital Elevation Database v4.1, (http://srtm.csi.cgiar.org/) 
